\title{
A VIOLÊNCIA SEXUAL INFANTIL NO BRASIL E A CULTURA DO ESPETÁCULO MIDIÁTICO
}

\author{
Ricardo Aparecido da Paixão \\ Mestrando em Educação pela Universidade Federal de Mato Grosso do Sul (PPGEdu/UFMS) \\ Bolsista CAPES \\ ricardoappaixa01979@gmail.com
}

Antônio Carlos do Nascimento Osório Doutor em Educação (Currículo) pela Pontifícia Universidade Católica de São Paulo (PUC-SP) Professor da Universidade Federal de Mato Grosso do Sul (UFMS) antonio.osorio@ufms.br

Anailton de Souza Gama Doutor em Letras pela Universidade Presbiteriana Mackenzie (UPM) Professor da Universidade Estadual de Mato Grosso do Sul (UEMS) anailtongama@yahoo.com.br

\section{RESUMO}

O presente trabalho consiste num esforço de mapeamento das possíveis alianças discursivas que acreditamos contribuírem para configuração do campo político conservador-liberal estabelecido hoje no Brasil. Para a realização dessa tarefa, utilizamos o conceito de formação discursiva, inaugurado nos trabalhos Foucault e posteriormente revisto nos desenvolvimentos trazidos por Michel Pêcheux, entendendo que um campo político responde a um sistema particular de coerções discursivas. Além disso, aproveitamos a translinguística bakhtiniana, e a extensão que Oswald Ducrot lhe acrescenta, a fim de desmembrar as vozes que se articulam em cada um desses sistemas discursivos, podendo assim melhor identificálas em sua especificidade. Nas formulações argumentativas, observamos que um caminho frequentemente utilizado na composição lógica de enunciados correspondentes a vozes ideológicas distintas é a colaboração enunciativa por via de pontos de contato semânticos e axiológicos entre as proposições.

Palavras-chave: dialogismo, interdiscursividade, formações discursivas.

\section{ABSTRACT}

The present paper consists in an effort to map the possible discursive alliances which are believed to contribute to the configuration of the political liberal conservatism recently established in Brazil. To accomplish this task, the concept of discursive formation is used, a concept firstly introduced by Foucault and further developed by Michel Pêcheux, understanding that a political field responds to a particular system of discursive coercions. In addition, Bakhtinian translinguistics and Oswald Ducrot's contributions to the concept are also used, to dismember the voices articulated in each of the discursive systems, so we can more effectively identify them in their specificity. In the argumentative formulations, we observe that a path frequently used in the logical composition of statements corresponding to distinct ideological voices is the enunciative collaboration through semantic and axiological points of contact between propositions.

Keywords: dialogism, interdiscursivity, discursive formations. 


\section{Introdução}

Pesquisar a questão da violência sexual infantil efetuando um determinado recorte histórico pode provocar, à primeira vista, um efeito de estranhamento, porém, apesar de o tema representar um "tabu" na sociedade, percebe-se claramente que há uma demanda para sua discussão e, nesse sentido, a academia não se pode furtar a participar desse debate.

Nosso ponto de partida será a constatação de que os meios de circulação são espaços de enunciação e contexto dos discursos, pois a linguagem da mídia é, até certo ponto, reflexo e expressão da ideologia dominante, dos valores em que se acredita, manifestando-se na maneira de ver o mundo em certo espaço da história.

A relevância deste estudo está em apresentar um panorama da violência sexual infantil no Brasil com vistas a compreender a dinâmica desse tema na atualidade procurando contribuir para a disseminação de reflexões sobre o papel e a função da mídia bem como a "cultura do espetáculo" (GREGOLIN, 2003) e a sua contribuição/massificação diante do tema na contemporaneidade. Assim, esse artigo surge a partir desse olhar cidadão na busca de uma melhor compreensão da problemática que envolve a criança vítima de violência sexual.

A percepção de que os meios de comunicação constroem discursivamente uma espetacularização dos acontecimentos está esboçada, por exemplo, em um trabalho de Michel Pêcheux produzido em 1983 denominado Discurso: estrutura ou acontecimento, publicado pela Editora Pontes em 1997. A mídia constrói uma "univocidade lógica" fazendo com que o acontecimento se torne uma proposição estabilizada. O objeto desta 
pesquisa são os discursos que circulam nos meios de comunicação, em especial na revista Veja.

Este artigo está organizado da seguinte forma: primeiramente apresentamos o percurso teórico da análise do discurso de linha francesa que nos serve de suporte e desenhamos uma narratividade da prática da violência sexual infantil. Posteriormente, analisamos os sentidos de "violência sexual infantil" e "violência simbólica".

\section{Das bases teóricas da Análise do Discurso}

Nos anos 1960, a Análise do Discurso (AD) se constitui no espaço de questões criadas pela relação entre três domínios disciplinares que são, ao mesmo tempo, uma ruptura com o século XIX: a linguística, o Marxismo e a Psicanálise. Este artigo inscreve-se na perspectiva da AD Francesa considerando que ela articula, em seus fundamentos, a linguística (Saussure), o marxismo (releitura de Althusser) e a psicanálise (releitura de Lacan). Não se trata apenas de relacionar esses três campos em suas especificidades, mas de verificar como eles estão relacionados e como a $A D$ concebe teoricamente esses campos e fundamenta-se para compreender um aspecto do funcionamento da linguagem

e de "interpretar" os sentidos e os sujeitos e seus aspectos materiais na relação inseparável com o sócio-histórico.

Afastando-se uma linguística puramente formal, essa linha teórica busca investigar a língua em uso, privilegiando não só forma, mas função e, sobretudo, processo. A visão estruturalista da descrição das propriedades formais da língua como sistema é substituído por uma visão mais desafiadora da descrição de como as pessoas interagem através da linguagem e da interpretação das funções que se realizam em uma forma linguística 
presente em um discurso contextualizado, enfocando a língua dentro de um contexto sócio-histórico, evidenciando um compromisso maior com o lado social da linguagem.

Pêcheux (2006, p. 160) argumenta que "as palavras, as expressões, as proposições, etc. mudam de sentido segundo as posições sustentadas por aqueles que as empregam", isto é, o sentido também está relacionado à posição que o sujeito ocupa no discurso, na sua relação constitutiva com as formações discursivas que os constituem. Em outras palavras, o sentido está para a posição sustentada pelo sujeito assim como o sujeito está para a formação discursiva que o interpela em alguma "região" ou espaço ideológico que marca determinada posição, ou seja, uma posição-sujeito; esta posição-sujeito constitui as disputas pelos sentidos e pelos espaços sociais.

Para Pêcheux (idem, p. 77), o discurso "é sempre pronunciado a partir das condições de produção dadas", ele "pode ser um ato político" que se "conjuga sempre sobre um discurso prévio, ao qual ele atribui um papel de matéria-prima". Assim, os discursos veiculados pela grande mídia referentes à violência sexual infantil são "práticas discursivas" que correspondem a certos efeitos de sentido (idem p. 164) das condições ideológicas de reprodução/transformação das relações de produção (idem, p. 180).

Para que uma sequência de elementos linguísticos seja considerada um enunciado é preciso que tenha existência material. A materialidade do enunciado remete às condições de possibilidade que o tornam repetível, obedecendo à ordem da instituição; o que significa dizer que o discurso não é um conjunto de signos, mas uma prática que abarca regras determinadas historicamente por se referir a um espaço, a um tempo dado e a uma área social geográfica, econômica e linguística.

Pêcheux (2006, p. 145) designa materialidade discursiva como "lugar material em que se realizam os efeitos de sentido". Há uma ideologia da comunicação social que faz 
com que se use a mídia verbalmente, isto é, de modo que as outras linguagens que constituem a mídia não funcionem sem o verbal. Para a $A D$, isso se constitui em efeito. No verbal e nas análises linguísticas, em geral, trata-se o signo sob a ilusão referencial, ou seja, a ilusão da literalidade.

\section{Do gênero discursivo}

Segundo Charaudeau (2006, p. 105), "todo dispositivo formata a mensagem e, com isso, contribui para Ihe conferir o sentido. Não há, conforme sabem os linguistas ou os poetas, forma sem suporte, significante sem significado e nem mensagem sem suporte."

Para a linguística, pensar o estudo dos gêneros passa a ser uma constante a partir do momento em que os estudos da linguagem se voltaram para o texto e se abriram para além do texto literário considerado, à época, como modelo a ser seguido.

As mídias constituem uma instância que não promulga nenhuma regra de comportamento, nenhuma norma, nenhuma sanção. Mais que isso, as mídias e a figura do jornalista não têm nenhuma pretensão de orientação nem de imposição, declarandose, ao contrário, instância de denúncia do poder. Ao mesmo tempo, as mídias não transmitem o que ocorre na realidade social, elas impõem o que constroem do espaço público. Aplicando essas reflexões ao nosso tema, ousaríamos questionar: qual o limite da "informação", "comunicação"? Onde termina a informação e começa o espetáculo?

A informação é uma questão de linguagem e sabe-se que a linguagem não é transparente, apresentando sua própria opacidade através da qual se constrói uma visão, um sentido particular do mundo. As mídias dirigem-se a um grande número de pessoas. Como fazer isso a não ser despertando o interesse e tocando a afetividade do destinatário 
da informação? A não ser distribuindo "no mundo inteiro as mesmas simplificações e os mesmos clichês"? Como atingir tantas pessoas senão praticando a cultura do espetáculo?

As mídias estariam se violando e, sem se darem conta disso, tornando-se manipuladoras, pois reproduzem exatamente o que o povo quer ver: o espetáculo. Em outras palavras, segundo Charaudeau (idem) "as mídias manipulam tanto quanto manipulam a si mesmas".

\section{Sobre a história da violência contra crianças}

A narratividade é importante para compreendermos a concepção da criança na história da humanidade e, consequentemente, compreendermos a concepção de criança na contemporaneidade confrontando com concepções que, ainda com resquícios da sociedade machista, classista, adultocêntrica e racista, propaga práticas e mentalidades que destituem crianças e adolescentes de seus direitos.

De acordo com Faleiros \& Faleiros (2008), em relação à violência contra crianças e adolescentes no cenário brasileiro, os autores afirmam que, desde seu descobrimento em 1500 até 1822, o Brasil foi uma colônia de Portugal, dependendo econômica, política e administrativamente do poder instalado em Lisboa. As leis e as ordens para as crianças também vinham de Portugal e eram aplicadas através da burocracia, dos representantes da corte e da Igreja Católica.

Havia grande mortalidade de crianças escravas. As mães eram alugadas como amasde-leite. Essa era uma maneira de separar os filhos de suas próprias mães. A criança escrava, mesmo depois da Lei do Ventre Livre, em 1871, podia ser utilizada pelo senhor desde os 8 até os 21 anos de idade. Antes dessa lei, as crianças escravas começavam bem 
cedo a trabalhar ou serviam de brinquedo para os filhos dos senhores. Era grande o número de filhos ilegítimos, muitos deles filhos de senhores com escravas. Os filhos nascidos fora do casamento, com raras exceções, eram fadados ao abandono, o que caracteriza uma humilhação, consequentemente uma violência. A narratividade apresentada neste item evidencia que maus tratos, violência e abandono marcaram a trajetória da infância pobre no Brasil.

A Constituição Brasileira, o Estatuto da Criança e do Adolescente (ECA) e a Normativa Internacional nessa área têm como base a teoria da universalidade dos direitos humanos, elaborada após a segunda guerra mundial, cujo propósito é resgatar as ideias da revolução francesa, reconhecendo que todos os homens nascem livres e iguais em dignidade e direitos, são dotados de razão e consciência e devem agir em relação uns aos outros com espírito de fraternidade e os direitos peculiares à pessoa em desenvolvimento.

As crianças e adolescentes têm os mesmos direitos assegurados para os adultos, mas por sua "vulnerabilidade" e "hipossuficiência bio-psicossocial" se faz necessária a doutrina da proteção à infância e à juventude. Embora os adultos sejam socialmente responsáveis e autorizados a exercer poder protetor sobre crianças e adolescentes, esse poder deve ser exercido de forma adequada. No entanto, é ainda corrente em instituições brasileiras - família, escola, igrejas, serviços de assistência e de ressocialização - a defesa e o exercício de uma pedagogia perversa de submissão de crianças e adolescentes ao poder autoritário, arbitrário e violento dos adultos.

Para fins de contextualização, a violência estrutural é uma forma de violência cumulativa e excludente. Exemplos atuais da violência estrutural são os altos índices de mortalidade de crianças e adolescentes provocada por causas externas, ligadas ao tráfico 
de drogas, atuação de gangues e extermínio de adolescentes em conflito com a lei, bem como homicídios e acidentes de toda ordem. Para ilustrar o que aqui expomos, convém lembrarmos de alguns programas televisivos que abordam a questão da violência. Destacamos a série FALCÃO MENINOS DO TRÁFICO apresentado no Fantástico, via Rede Globo, que teve como inspiração o trabalho de noventa horas de filmagens do Rapper carioca MV Bill, ao comprovar que as crianças e adolescentes buscam refúgio na marginalidade em resposta à sociedade que tem seus valores voltados para o desenvolvimento, oferece o descaso.

Por outro lado, a violência física contra crianças e adolescentes é uma relação social de poder que se manifesta nas marcas que ficam principalmente em seus corpos, machucados, com lesões, ferimentos, fraturas, queimaduras, traumatismos, hemorragias, escoriações, lacerações, arranhões, mordidas, equimoses, convulsões, inchaços, hematomas, mutilações, desnutrição e, muitas vezes, levando-os até a morte. São formas de violência física: a disciplina física abusiva com fins corretivos (tapas, surras e agressões com qualquer tipo de objeto), torturas, privações físicas deliberadas (de comer e de beber), restrições de movimentos (confinamento), privação ou transferência de abrigo (expulsão do lar, colocação em outra residência, internação).

A violência psicológica, de acordo com Faleiros \& Faleiros (2008), é uma relação de poder desigual entre adultos dotados de autoridade e crianças e adolescentes dominados. Esse poder é exercido através de atitudes de mando arbitrário, de agressões verbais, de chantagens, de regras excessivas, de ameaças (inclusive de morte), humilhações, desvalorização, estigmatização, desqualificação, rejeição, isolamento, exigência de comportamentos éticos inadequados ou acima das capacidades e de exploração econômica ou sexual. Essa violência provoca traumas psicológicos que 
afetam o psiquismo, as atitudes e as emoções, traduzindo-se até mesmo na incapacidade da criança em interagir socialmente dentro das condições consideradas próprias de sua idade, podendo tornar-se passiva ou agressiva. Não é raro que a vítima tenha uma imagem deteriorada de si mesma, com baixa estima ou depressão.

A violência psicológica situa-se no conceito geral de violência como uso ilegítimo da autoridade decorrente de uma relação de poder. Assim, no lugar de oferecer a proteção, que é o seu dever, o adulto se relaciona com a criança por meio da agressão verbal ou psicológica e do domínio, substituindo e invertendo o papel que dele se espera.

Ainda, para Faleiros \& Faleiros (2008), o abuso sexual contra crianças e adolescentes é um relacionamento interpessoal sexualizado, privado, de dominação perversa, geralmente mantido em silêncio e segredo. Nas situações de abuso sexual, crianças ou adolescentes são usados para gratificação de um adulto ou mesmo de um adolescente mais velho, com base em uma relação de poder que pode incluir desde manipulação da genitália, mama, ânus, exploração sexual, voyeurismo, pornografia, exibicionismo, até o ato sexual com ou sem penetração, com ou sem violência. A dominação sexual perversa é uma construção deliberada, paciente e ritualizada de um relacionamento perverso que se mantém através da dominação psicológica de longa duração.

Considerando a diversidade de possibilidades de constituição do corpus e as etapas do percurso metodológico, optamos pela coleta de discursos sobre a violência sexual infantil na mídia impressa, totalizando 11 enunciados que serão analisados. Esses discursos sobre a violência sexual infantil foram coletados, numerados e agrupados em enunciados significativos de discursos, sendo classificados os discursos quanto às suas 
especificidades de sentidos e posições-sujeito, bem como analisada as relações internas e externas dos discursos em filiações históricas.

\section{Categorias discursivas}

De acordo com Maingueneau (2005. p. 59), existem vários tipos de categorias discursivas, tais como: conversa, manual, jornal, tragédia, reality show, romance sentimental, descrição, polêmica, soneto, narrativa, semanário, panfleto, relatório de estágio, mito, cartão de boas festas etc. No entanto, elas variam conforme as usamos. Para Maingueneau (idem): "tais categorias correspondem às necessidades da vida cotidiana e o analista do discurso não pode ignorá-las, mas também não pode contentarse com elas, se quiser definir critérios rigorosos". A seguir, agrupamos os recortes discursivos em categorias.

\subsection{Discurso psicológico}

Entendemos como Discurso Psicológico o discurso que possui conotações que, de certa forma, se relacionam ou trazem em si características psicológicas. Tomando o dicionário enquanto discurso, o vocábulo Psicologia (NASCENTES, 2002, p. 518) significa "s.f. Ciência que estuda os fenômenos psíquicos e o comportamento do ser humano quando reage globalmente às situações externas ou a necessidades internas; conjunto de estados e de disposições psíquicas de um indivíduo ou de uma classe de indivíduos [...]". Aplicado ao nosso objeto de estudo, temos os seguintes recortes: 
R1 - [...] Em lugar do cuidado que a sua fragilidade física e emocional requer, elas são confrontadas com surras e violência psicológica para que fiquem caladas e continuem a ser violadas por seus algozes impunes. (grifos nossos)

No recorte em epígrafe, encontramos verbetes que denunciam, de certa forma, a cultura do espetáculo midiático. Observa-se que o termo "fragilidade física" está ligado não só à questão do corpo, mas também à impotência desse corpo diante do agressor. Ao mesmo tempo, o termo "fragilidade física e emocional" reforça esse tipo de violência caracterizada como Violência Psicológica. Pesquisa realizada pela revista Veja, edição 2104, de 18 de março de 2009, em reportagem intitulada "SILÊNCIO RASGADO" seguido do lide "Pedofilia na classe média: pais e padrastos são os agressores mais frequentes e as meninas a totalidade das vítimas [...]" ilustra bem essa realidade:

Figura 1 - Pedofilia na classe média (Revista Veja)

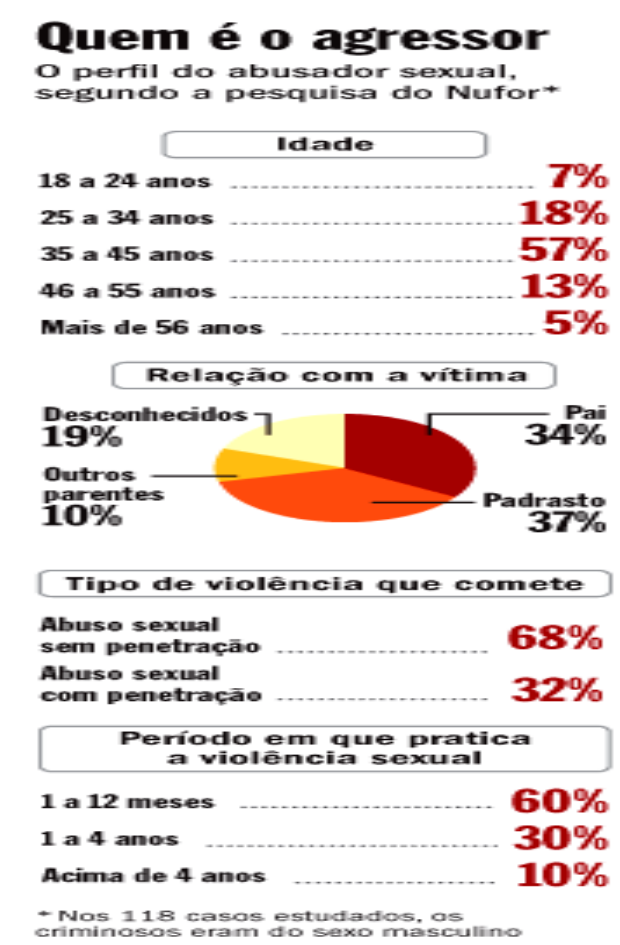

Fonte: Revista Veja. Edição 2104, de 18/03/2009 
Atentando para o título da reportagem de capa da revista Veja, edição 2105, de 25 de março de 2009, "PEDOFILIA: Quando o inimigo é da família", verifica-se que se trata de uma reportagem sobre violência sexual infantil quando, no interior da revista, a reportagem intitulada "Violadas e Feridas. Dentro de casa" mostra-nos casos desse tipo de violência que, segundo a revista, "a maioria dos molestadores sexuais de crianças tem a confiança das vítimas: são seus pais, padrastos ou parentes".

O recorte em epígrafe denuncia que "elas são confrontadas com surras e violência psicológica para que fiquem caladas e continuem a ser violadas por seus algozes impunes".

Por sua vez, o vocábulo algozes, segundo Nascentes (2002, p. 30) significa "s.m. homem encarregado de executar a alta justiça [...] pessoa desumana, cruel, perseguidora, torturadora [...] que, aplicado ao nosso recorte, justifica o conceito de violência psicológica aliada à violência sexual.

R2 - [...] No vasto cardápio de vilezas que um ser humano é capaz de perpetrar contra um semelhante, o abuso sexual de meninas e meninos é dos mais abjetos em especial quando é cometido por familiares.

R3 - [...] Estima-se que, no Brasil, a cada dia, 165 crianças ou adolescentes sejam vítimas de abuso sexual. A esmagadora maioria deles, dentro de seus lares.

R2 e R3, além de inserirem-se na categoria discursiva da psicologia e da violência psicológica e violência sexual infantil, podem constituir-se como o discurso da revolta, tendo em vista que a revista Veja, posicionando-se como formadora de opinião, denuncia "o vasto cardápio de vilezas", sendo que o "abuso sexual de meninas e meninos é dos 
mais abjetos". Além de denunciar que "a cada dia, 165 crianças e adolescentes [...] são vítimas de abuso sexual", corroborando os dados da estatística anterior, afirmando que "a esmagadora maioria deles, dentro de seus lares".

Conforme exposto anteriormente, as mídias dirigem-se a um grande número de pessoas. Como fazer isso a não ser despertando o interesse e tocando a afetividade do destinatário da informação?

\subsection{Discurso da perplexidade}

Segundo Nascentes (2002, p. 483), perplexidade é "s.f. estado de perplexo; irresolução; hesitação [...]". Por sua vez, perplexo é "adj. que se sente indeciso, irresoluto".

R4 - [...] Quando, há três semanas, G. chegou ao hospital carregando uma sacola de brinquedos, os médicos encarregados do procedimento ficaram atônitos: não tinham ideia da quantidade de medicamentos que deveriam usar numa gestante tão diminuta - G. mede 1,36 metros e pesava então 33 quilos.

R4 mostra o discurso da perplexidade: "os médicos encarregados do procedimento ficaram atônitos" diante de "[...] uma gestante tão diminuta". A reportagem, a mesma indicada na seção anterior, mostra G.M.B.S., engravidada pelo padrasto aos 9 anos de idade. A reportagem mostra ainda mais a perplexidade quando revela que "sua mãe decidiu que ela, grávida de gêmeos, deveria ser submetida a um aborto". O recorte em epígrafe revela que "G. mede 1.36 metros e pesava então 33 
quilos". O que aumenta ainda mais a perplexidade do leitor diante da "cultura do espetáculo" que a mídia provoca em torno do acontecimento.

O que se percebe em $\mathrm{R} 4$ a respeito da mídia é que ela não promulga nenhuma regra de comportamento, nenhuma norma, nenhuma sanção: a figura do jornalista não tem nenhuma pretensão de produção de efeito de sentido nem de imposição, declarando-se, ao contrário, instância de denúncia de poder. Ao mesmo tempo cabe aqui um questionamento: onde termina a informação e começa o espetáculo?

\subsection{Discurso da tradição}

Segundo Nascentes (2002, p. 630), o vocábulo tradição significa “[...] doutrinas, ritos, costumes, feita de pais e filhos no correr dos tempos e de geração em geração; notícia de um fato antigo transmitida por esse modo; doutrina, costume, etc., cuja conservação em um povo se faz pela transmissão de pais a filhos [...]".

Analisando os recortes abaixo, percebe-se que o mesmo se enquadra na categoria discursiva da tradição, tendo em vista que, segundo a definição, em determinadas localidades "a prática do incesto com meninas é vista como 'tradição'".

R7 - [...] Também é sobretudo nessa parte do Brasil, em localidades como a Ilha de Carapajó, no Pará, que a prática do incesto com meninas é vista como "tradição".

R8 - [...] "Costuma-se dizer que" "quem planta a bananeira tem direito de comer o primeiro fruto", explica Maria do Carmo Modesto, líder religiosa que coordena trabalhos sociais na região. 
R9 - [...] Já no interior do Nordeste, não é incomum que os "coronéis" das pequenas localidades recrutem crianças para satisfazer seus desejos bestiais.

Em R7, deparamo-nos com a prática do incesto que é tida como tradição nas regiões ribeirinhas do Amazonas, segundo a revista Veja - edição 2105 - de 25 de março de 2009. Em sua dissertação, a advogada Maíra Barreto lembra que é:

[...] o costume de um pai iniciar sexualmente suas filhas menores é aceitável. Essa combinação de incesto e pedofilia pode explicar, inclusive, a origem de uma lenda regional: a do boto que, em noites de lua cheia, se transforma em homem e engravida as virgens incautas. Muitos pesquisadores acreditam que o mito do boto serviria para encobrir os responsáveis por muitas das gestações infantis que ocorrem na região. 'Grande parte dos "filhos do boto' é fruto de incesto" (BARRETO, 2008).

Essa prática está inserida na classificação de violência sexual já discutida anteriormente. É uma violação de direitos, uma transgressão, uma relação de poder perversa e desestruturante. Observa-se em R8 o seguinte ditado "quem planta a bananeira tem direito de comer o primeiro fruto", recorte este que vem reforçar o discurso da tradição, reafirmando o recorte analisado anteriormente, justificando a prática do incesto. Discursos como esses reafirmam o tema central dessa pesquisa de que a violência sexual é uma prática que pode ser retomada historicamente.

Em relação à mídia, cabe aqui uma questão: o que é informação, comunicação e/ou espetáculo? Se "informação" e "comunicação" são termos que nos remetem a fenômenos sociais, caberia aqui a reflexão do que seria "informação" e "comunicação" e qual é o lugar do espetáculo veiculado via mídia. As mídias constituem uma instância que não promulgam nenhuma regra de comportamento, nenhuma norma, nenhuma sanção. 
Mais que isso, as mídias e a figura do jornalista não têm nenhuma intenção de comunicação nem de orientação, declarando-se, ao contrário, instância de denúncia do poder.

R9 nos mostra que, quanto mais recôndito o lugar (Nordeste, Amazonas), mais essas práticas consideradas tradicionais se perpetuam, o que não quer dizer que isso não ocorra nas grandes cidades.

\subsection{Discurso da revolta}

De acordo com Nascentes (2002, p. 554), “Revolta: s.f. Ato ou efeito de revoltar ou de revoltar-se; movimento destinado a voltar em movimento contrário, a subverter a ordem estabelecida; violenta perturbação moral, causada pela indignação; transtorno, agitação".

R10 - [...] Não tenho mais coragem de ficar longe dele e dos outros filhos, nem de deixá-los com ninguém. Perdi a confiança em todo mundo.

Em “[...] perdi a confiança em todo mundo", registrado em R10, vemos o discurso da revolta. Uma "violenta perturbação moral" de quem vivenciou ou participa do universo de quem sofreu a violência sexual. Em outras palavras, uma "revolta" causada pela "indignação". O discurso, em análise, é o recorte de uma reportagem veiculada pela revista Veja, edição 2105, de 25 de março de 2009, que aborda o tema da pedofilia em que a mãe se sente "revoltada" e "indignada" com o ocorrido em que seu filho foi a vítima. 
R11 - [...] Acho que nunca vou superar. Lembro do cheiro do protetor solar que ele usava. Não suporto senti-lo até hoje. Eu tinha nove anos e treinava natação com ele.

"Eu tinha nove anos e treinava natação com ele" é o recorte de uma reportagem também veiculada pela revista Veja (idem) em que a atleta denuncia o seu treinador por práticas sexuais abusivas. A prática sexual abusiva em crianças e adolescentes inverte a natureza das relações entre adultos e crianças/adolescentes definidas socialmente, tornando-as: desumanas em lugar de humanas; negligentes em lugar de protetoras; agressivas em lugar de afetivas; individualista e narcisistas em lugar de solidárias; dominadoras em lugar de democráticas; controladoras em lugar de libertadoras; perversas em lugar de amorosas; desestruturadoras em lugar de socializadoras. Em “[...] Acho que nunca vou superar" demonstra o discurso da revolta tendo em vista a "violenta perturbação moral, causada pela indignação".

\section{Considerações finais}

O tema "Violência Sexual Infantil" exigiu um esforço além de teórico, metodológico, exigiu um esforço no sentido de conceitos e valores, crenças e tradições. Esforços esses que se entranham no nosso consciente e que se tornam "normais" porque possuem a força do senso comum, a força da lei do mais forte, a força do homem macho, caçador, que se apodera de suas presas, indefesas ou não.

Ao mesmo tempo, o tema por nós escolhido reflete um certo tabu em nossa sociedade, é um tema envolto de silenciamentos. De silenciamentos porque faz calar suas 
vítimas seja por medo das ameaças; seja por constrangimento, seja para proteger seus agressores que se fantasiam em dóceis figuras.

Apresentamos uma narratividade da violência sexual no Brasil e deparamos, em pleno século XXI, com o legado do descaso.

Compreendemos, ao longo desta pesquisa, que a grande maioria das famílias no Brasil são protetoras, milhões delas ao custo de enormes sacrifícios. No entanto, também, nessas famílias protetoras, encontram-se traços culturais, em diferentes graus, de relações familiares adultocêntricas, machistas, autoritárias que as tornam mais ou menos violentas.

Estamos mais perto da violência sexual infantil do que gostaríamos e ela é mais extensiva do que imaginamos. Em função dessas características intensivas e extensivas da violência sexual infantil, sua desarticulação somente poderá ser alcançada se sua busca for adotada como um dever social de todos, em uma rede de proteção integral.

O papel da mídia é de manter a população informada. A população, por outro lado, não deve se colocar como mera receptora passiva daquilo que é veiculado pelos meios de comunicação. Para isso, é necessário que cada pessoa exercite sua atitude crítica, filtrando as informações recebidas, questionando-as, fazendo um contraponto e buscando, na opinião pública, uma opinião própria, particular, com a qual se identifique e na qual acredite.

Esperamos ter contribuído com os estudos da Linguagem e, principalmente, com a compreensão do conceito de "violência sexual infantil". Nossa pesquisa abre espaço para um amplo debate no meio acadêmico e social e essa é a função da Universidade.

\section{Referências}


BARRETO, Maíra de Paula. Da pedofilia e da pornografia infantil sob o prisma da universalidade dos direitos da personalidade. 2008. Dissertação (Ciências Jurídicas) Centro de Ensino Superior de Maringá, Maringá, PR.

CHARAUDEAU, D. O discurso das mídias. Tradução de Angela M. S. Correia. São Paulo: Contexto, 2006.

FALEIROS, Vicente de P.; FALEIROS, Eva S. A escola que proteger: enfrentando a violência contra crianças e adolescentes / Vicente de Paula. Brasília: Ministério da Educação, Secretaria de Educação Continuada, Alfabetização e Diversidade, 2008.

GREGOLIN, Maria do Rosário (Org.). Discurso e mídia: a cultura do espetáculo. São Paulo: Clara Luz, 2003.

MAINGUENEAU, D. Novas tendências em análise do discurso. 3 ed. Tradução de Freda Indursky. Campinas, SP: Pontes, 2005.

NASCENTES, Antenor. Dicionário da língua portuguesa da Academia Brasileira de Letras. Rio de Janeiro: Academia Brasileira de Letras, 2002.

PÊCHEUX. Michel. Análise automática do discurso (AAD-69). Tradução de Bethânia S. Mariani et al. 3 ed. In: GADE, F.; HAK, T. (Orgs.). Por uma análise automática do discurso: uma introdução a obra de Michel Pêcheux. Campinas, SP: Ed. da Unicamp, 2006.

Recebido em 16 de março de 2018. Aceito em 23 de abril de 2018. 